\title{
Resistência aos Mineralocorticóides: Pseudo-hipoaldosteronismo Tipo 1
}

\begin{abstract}
RESUMO
Pseudo-hipoaldosteronismo tipo 1 (PHA1) é uma doença genética rara, caracterizada por vômitos, desidratação, baixo ganho pôndero-estatural e perda urinária de sal no período neonatal. Indivíduos afetados apresentam hiponatremia, hipercalemia, aumento da atividade de renina plasmática e concentrações muito elevadas de aldosterona plasmática, secundárias a uma resistência renal ou sistêmica à aldosterona. A forma sistêmica do PHA1 é a mais grave, havendo necessidade de reposição de doses altas de $\mathrm{NaCl}$. Os sintomas persistem por toda a vida. Mutações inativadoras nos genes codificadores das sub-unidades do canal de sódio sensível à amilorida (ENaC) em homozigose ou heterozigose composta são responsáveis pelo quadro clínico de PHA1 sistêmico. A forma renal do PHA1 tem apresentação clínica mais leve, com necessidade de suplementação de doses baixas de $\mathrm{NaCl}$. Os sintomas regridem no final do primeiro ano de vida. Mutações inativadoras do gene do receptor do mineralocorticóide (MR) estão associadas à forma renal do PHA1 em várias famílias afetadas. O padrão de herança é autossômico dominante, entretanto casos esporádicos têm sido relatados. No presente trabalho, discutimos as ações e os mecanismos de ação da aldosterona, e os aspectos clínicos e fisiopatológicos envolvidos nas síndromes de resistência aos mineralocorticóides. Adicionalmente, os aspectos clínicos e moleculares de uma família brasileira com PHA1 secundário à mutação R947X no gene do MR são discutidos. (Arq Bras Endocrinol Metab 2007;51/3:373-381)
\end{abstract}

Descritores: Pseudo-hipoaldosteronismo tipo 1; Aldosterona; Receptor do mineralocorticóide; $\mathrm{ENaC}$

\section{ABSTRACT}

Mineralocorticoid Resistance: Pseudohypoaldosteronism Type 1.

Pseudohypoaldosteronism type 1 (PHA1) is a rare genetic disease characterized by neonatal renal salt wasting, vomiting, dehydration and failure to thrive. Affected patients present hyponatremia, hyperkalemia, associated with high levels of plasma renin and aldosterone resulting from a renal or systemic resistance to aldosterone. The systemic form of PHA1 results in a severe phenotype, and high doses of salt supplementation are necessary. The symptoms are lifelong recurrent. This form is associated with autosomal recessive transmission. Homozygous or compound heterozygous loss of function mutations in the genes coding for the epithelial sodium channel $(\mathrm{ENaC})$ subunities are responsible for this disease. The renal form of PHA1 results in a mild phenotype. Low doses of salt supplementation are required and usually the symptoms remit at the end of the first year of life. Heterozygous loss-of-function mutations in the mineralocorticoid receptor $(M R)$ gene are associated with the renal form of PHA1 in the majority of the affected families but sporadic cases have been reported. In this review the mechanisms of aldosterone action and its effects are discussed. Additionally, clinical and molecular findings of a Brazilian family with the renal form of PHA1 caused by a nonsense mutation (R947X) in the $M R$ gene are presented. (Arq Bras Endocrinol Metab 2007;51/3:373-381)

Keywords: Type 1 pseudohypoaldosteronism; Aldosterone; Mineralocorticoid receptor; ENaC

\section{revisão}

FÁBIO L. FERNANDES-ROSA
SONIR R.R. ANTONINI

Endocrinologia Pediátrica, Departamento de Puericultura e Pediatria, Faculdade de Medicina de Ribeirão Preto USP, SP.

Recebido em 03/08/06 Revisado em 18/10/06 Aceito em 22/10/06 
$\mathrm{O}$ MINERALOCORTICÓIDES SÃO HORMÔNIOS esteróides envolvidos na regulação de sódio e água corporal através da regulação do transporte de sódio em tecidos epiteliais. Além disso, exercem efeitos importantes sobre o sistema cardiovascular e o sistema nervoso central. A aldosterona é o principal mineralocorticóide humano e desempenha um papel crucial na regulação da pressão arterial e homeostase eletrolítica $(1,2)$. Os principais efetores da ação da aldosterona nos tecidos epiteliais são o receptor do mineralocorticóide $(\mathrm{MR})$ e o canal de sódio sensível à amilorida (ENaC). Alterações na cascata de sinalização celular da aldosterona podem resultar em hipertensão ou em síndrome de resistência aos mineralocorticóides (pseudo-hipoaldosteronismo tipo 1).

\section{AÇŌES DA ALDOSTERONA}

A aldosterona é a molécula efetora final do sistema renina-angiotensina e atua nas células epiteliais do néfron distal e do cólon promovendo a reabsorção de sódio e excreção de potássio. A água segue o movimento do sódio via osmose, estabilizando o volume plasmático e conseqüentemente a pressão arterial (3).

A aldosterona exerce efeitos diretos importantes sobre o sistema nervoso central e sobre o balanço energético. Assim como os glicocorticóides, a ação dos mineralocorticóides altera a atividade do hipocampo, contribuindo para adaptações do comportamento em resposta ao estresse (4). Além disso, estudos recentes mostraram que a aldosterona é capaz de regular a diferenciação de adipócitos e a termogênese, sugerindo um papel dos mineralocorticóides na regulação do balanço energético (5-7).

A elevação da pressão arterial pode ser induzida pela aldosterona através da ativação dos MRs em regiões circunventriculares no sistema nervoso central (8). A aldosterona age também modulando o tônus vascular, possivelmente aumentando a resposta pressórica induzida por catecolaminas e por ação nos receptores de angiotensina II (9). Adicionalmente, a aldosterona promove a deposição de colágeno em vasos sangüíneos e músculo cardíaco, favorecendo a fibrose e hipertrofia cardíaca $(10,11)$. Em concordância com estes achados, existem evidências de benefício clínico do uso de bloqueadores do receptor da aldosterona em pacientes com insuficiência cardíaca ou infarto agudo do miocárdio complicado por disfunção do ventrículo esquerdo e falência cardíaca $(12,13)$.

O efeito principal da aldosterona nos tecidos epiteliais é promover a reabsorção de sódio e a secre- ção de potássio e hidrogênio. O transporte de sódio pela membrana apical de tecidos epiteliais (túbulo distal renal, cólon distal, glândulas sudoríparas e salivares) é mediado pelo $\mathrm{ENaC}$ e representa o passo limitante no transporte iônico regulado pela aldosterona (14). O transporte ativo pela membrana basolateral é catalisado pela bomba de sódio e potássio ATP dependente $(\mathrm{Na} / \mathrm{K}$ ATPase $)(15)$.

\section{Mecanismo molecular de ação da aldosterona}

A aldosterona regula o transporte iônico ao se ligar a um receptor intracelular, o MR (figura 1 ). $\mathrm{Na}$ ausência do hormônio, o MR é encontrado predominantemente no citoplasma associado a um complexo protéico composto por proteínas de choque térmico (hsp), incluindo hsp90 e hsp70, imunofilinas como FKBP52 e FKB54 e ciclofilina CYP40. A ligação ao hormônio induz modificação conformacional do receptor, dissociação do complexo hétero-oligomérico e fosforilação do $\operatorname{MR}(3,14,16)$.

Após a ligação ao hormônio, o MR, na forma de homodímeros, transloca-se até o núcleo onde se liga a elementos específicos do ácido desoxirribonucléico (DNA) localizados em regiões regulatórias de genes-alvo. Genes codificadores das sub-unidades das proteínas $\mathrm{Na} / \mathrm{K}$ ATPase e do $\mathrm{ENaC}$ são regulados pela aldosterona (17). Outros genes responsivos à aldosterona no epitélio renal foram descobertos recentemente: Sgk-1, Ki-RasA, CHIF, NDRG2 e GILZ. As proteínas codificadas por estes genes estão implicadas na fase rápida de transporte de sódio estimulado pela aldosterona (18-23). Na figura 1 está representado o modelo de ação genômica da aldosterona.

A resposta do $\mathrm{ENaC}$ à aldosterona pode ser dividida em três fases: latente, que dura aproximadamente 45 minutos e não há efeito discernível na atividade do canal; a fase rápida, que dura de $45 \mathrm{mi}-$ nutos a 3 horas, e a fase tardia, de 3 horas a vários dias. $\mathrm{Na}$ fase rápida de ação da aldosterona, já ocorre a reabsorção de sódio e água, mesmo sem aumento do RNAm da sub-unidade $\Delta$ do $\mathrm{ENaC}$, que só ocorre na fase tardia de ação. Este fato sugere que a aldosterona induza ou reprima genes envolvidos na inserção do $\mathrm{ENaC}$ na superfície celular ou nas suas propriedades. Os genes $S g k-1$ e $K i$-Ras- $A$ parecem estar envolvidos nesse processo (24).

A aldosterona apresenta, também, um mecanismo de ação não-genômico nos tecidos epiteliais e nos tecidos vascular e cardíaco, com efeitos semelhantes ao mecanismo genômico, porém significativamente mais rápidos. Até o momento, nenhum re- 


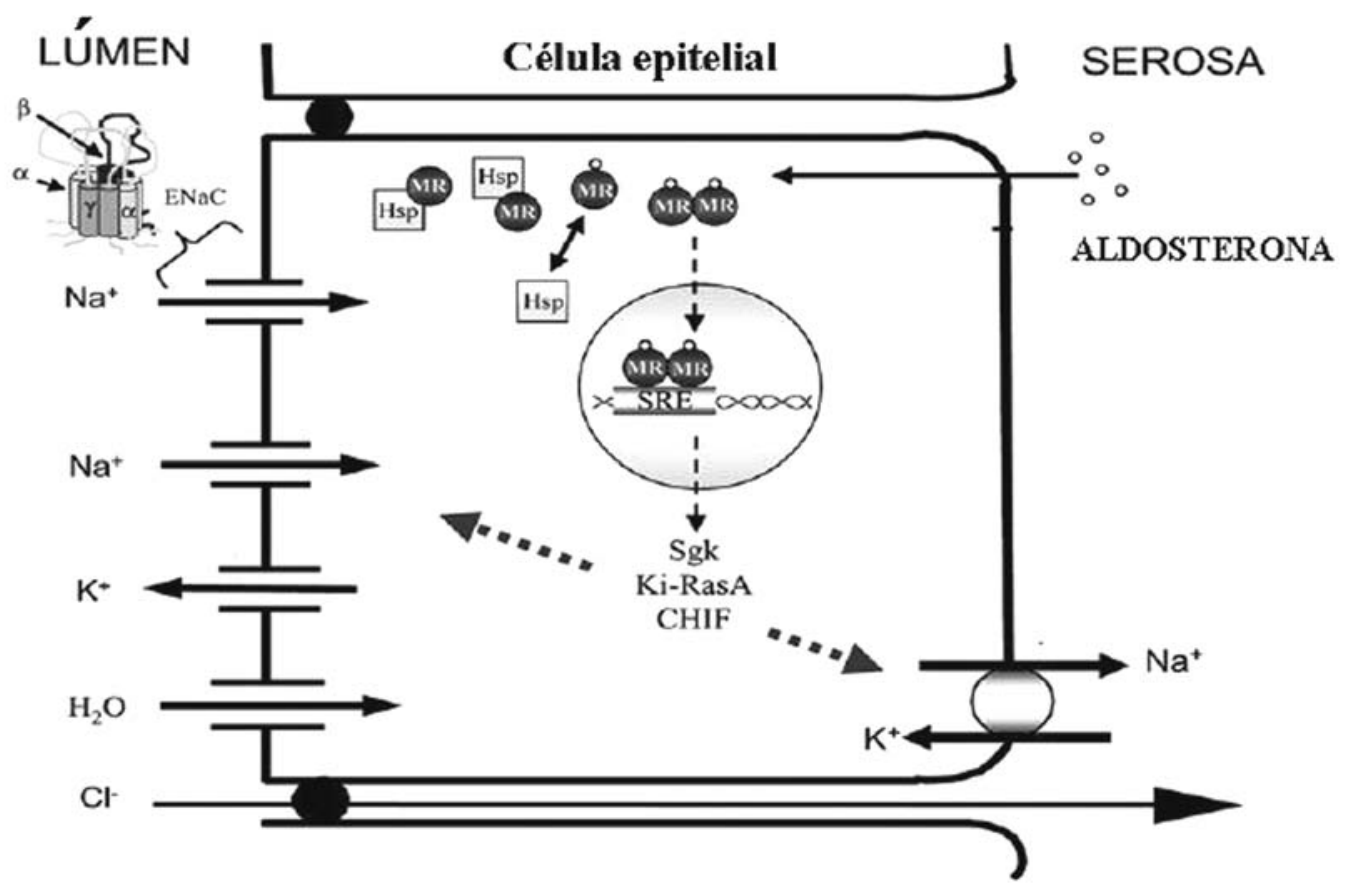

Figura 1. Modelo de ação genômica da aldosterona em célula epitelial. A aldosterona liga-se ao MR, o qual dissocia do complexo com Hsp, homodimeriza-se e transloca-se até o núcleo onde se liga aos elementos responsivos aos esteróides, induzindo a síntese de proteínas, entre elas a SGK, Ki-RasA e CHIF. Estas proteínas aumentam a ação do ENaC durante a fase rápida de ação. Posteriormente, o MR induz a síntese de sub-unidades do $\mathrm{ENaC}$ e de componentes da bomba $\mathrm{Na} / \mathrm{K}$ ATPase. Hsp: proteína de choque térmico, ENaC: canal de sódio sensível a amilorida, MR: receptor do mineralocorticóide, SRE: elementos responsivos aos esteróides. [Adaptado de Booth e cols., 2002 (3)]

ceptor de membrana para a aldosterona foi isolado e grande parte dessas ações não-genômicas parece ser mediada pelo $\mathrm{MR}$, porém o mecanismo pode variar entre os tecidos. O papel fisiológico dessas ações nãogenômicas ainda não foi estabelecido (25).

\section{PSEUDO-HIPOALDOSTERONISMO TIPO I}

O PHAl é uma doença genética rara, descrita inicialmente em 1958. Indivíduos afetados apresentam perda de sal no período neonatal, desidratação, hipotensão arterial, hipercalemia e acidose metabólica. $\mathrm{O}$ diagnóstico é estabelecido pela presença de concentrações plasmáticas elevadas de aldosterona e de renina em vigência do quadro clínico de hipoaldosteronismo $(26,27)$. No PHAl existe um defeito no transporte de sódio no néfron distal, secundário a uma resistência à ação dos mineralocorticóides. Existem duas formas de PHAl, a forma sistêmica, com padrão de herança autossômico recessivo, e a forma restrita aos rins, com padrão de herança autossômico dominante (28-31).

Em estudos de pacientes com resistência à aldosterona, permanece incerta a correlação entre concentração de aldosterona e doença cardiovascular, visto que indivíduos com PHAl apresentam concentrações elevadas de aldosterona por toda a vida. Geller (2), estudando os familiares de pacientes com a forma renal do PHAl, não encontrou diferenças significativas em relação aos parâmetros de ação da aldosterona entre os indivíduos afetados ou não. Nos dois grupos foram similares a pressão arterial sistólica e diastólica, a natremia e a calemia, a fração de excreção de sódio e o gradiente transtubular de potássio. A única diferença significativa entre os dois grupos foi a concentração plasmática de aldosterona, que foi maior no grupo de indivíduos assintomáticos carreadores da mutação R537X no gene do MR (2).

\section{PHA1 - forma sistêmica}

A forma autossômica recessiva do PHAl (OMIM \#264350), também chamada de forma sistêmica, é a mais grave, pois leva à perda de sal em diversos órgãos e tecidos como as glândulas salivares, glândulas sudoríparas, epitélio colônico, rins e pulmões. Os sintomas persistem por toda a vida e há a necessidade de reposição de grande quantidade de sódio para a sobrevivência dos indivíduos afetados. Em formas mais 
graves, ocorrem infecções pulmonares de repetição, podendo simular quadro clínico de fibrose cística (3234). A forma sistêmica do PHAl é causada por mutações nos genes codificadores das sub-unidades $\Delta, \Delta$ e $\Delta$ do $\mathrm{ENaC}$ (35-38).

\section{ENaC}

O ENaC está localizado na membrana apical de células epiteliais polarizadas, onde faz a mediação do transporte transepitelial de sódio. Nos rins, o ENaC é encontrado no néfron distal, onde a reabsorção de sódio é controlada pela aldosterona (39). Sob condições fisiológicas, a reabsorção de sódio no néfron distal representa somente $5 \%$ do total filtrado; entretanto, esta reabsorção pode aumentar consideravelmente em resposta à secreção de aldosterona ou de vasopressina. Esse controle hormonal é essencial para o ajuste "fino" da reabsorção salina no néfron distal e para a manutenção do balanço hidro-salino (40).

$\mathrm{O} \mathrm{ENaC}$ é composto por três sub-unidades homólogas $(\Delta, \Delta$ e $\Delta)$. Cada sub-unidade apresenta dois domínios hidrofóbicos altamente conservados $(\mathrm{Hl}$ e H2), uma grande alça extracelular e as regiões transmembrana (M1 e M2) $(41,42)$. Mutações inativadoras em homozigose nos genes codificadores das sub-unidades do ENaC levam à falência na reabsorção de sódio com conseqüente perda de sal em diversos órgãos-alvo. Indivíduos heterozigotos para mutações nos genes codificadores do $\mathrm{ENaC}$ apresentam concentrações plasmáticas de aldosterona e renina normais (35-38). Até o momento, 16 mutações nos genes codificadores das sub-unidades do $\mathrm{ENaC}$ foram descritas
$(35,36,38,43-46)$ (tabela 1$)$.

\section{PHA1 - forma renal}

A forma renal do PHAl (OMIM \#177735), também denominada de forma autossômica dominante, é caracterizada por uma resistência predominantemente renal à ação da aldosterona. Os pacientes com a forma renal do PHAl apresentam melhora clínica importante com a reposição de doses mais baixas de $\mathrm{NaCl}$ ( 1 a 2 $\mathrm{g} /$ dia) durante o primeiro ano de vida. Após este período, a suplementação da $\mathrm{NaCl}$ pode ser suspensa e o paciente permanece clinicamente assintomático, a despeito de as concentrações de aldosterona e atividade de renina plasmática (PRA) elevarem-se significativamente (32). A forma renal do PHAl é secundária, na maioria dos casos, a mutações inativadoras no gene do $M R$ (tabela 2) (1,27,47-53).

A forma renal do PHAl é caracterizada por remissão dos sintomas e normalização eletrolítica no final do primeiro ano de vida (32). Uma possível explicação para esta melhora seria o aumento da concentração de sal na dieta de lactentes quando da transição de aleitamento materno exclusivo (dieta com baixa concentração de sódio) para dieta mista, sugerindo uma interação genética-ambiental. Neste caso, em uma dieta com baixa ingestão de sódio, o neonato e o lactente seriam dependentes de uma ativação máxima do sistema renina-angiotensina-aldosterona e a haploinsuficiência do $\mathrm{MR}$ resultaria em depleção de volume e hipercalemia (2). Em ratos trangênicos, knockout para o gene do MR, foi verificada a estimulação da atividade do ENaC pelos glicocorticóides, podendo ser esta uma possível via de estimulação do

Tabela 1. Mutações descritas nos genes codificadores das sub-unidades do ENaC.

\begin{tabular}{|c|c|c|c|}
\hline Nucleotídeo & Códon & Transmissão & Referência \\
\hline$\Delta 302 \mathrm{del} T C$ & $\Delta 168, F$ & Homozigose & 35 \\
\hline$\Delta 1621 \mathrm{C}>\mathrm{T}$ & $\Delta \mathrm{R} 508 \mathrm{X}$ & Homozigose & $35,43,45$ \\
\hline$\Delta 604$ delAC/ $\Delta 1404$ delC & T169F/F435F & Heterozigose composta & 43 \\
\hline$\Delta 256 \mathrm{C}>\mathrm{T} / \Delta$ del éxons $3-4$ & $\Delta \mathrm{R} 53 \mathrm{X} /$ proteína anômala & Heterozigose composta & 43 \\
\hline$\Delta 828 \mathrm{del} / \Delta 1449 \mathrm{delC}$ & $\Delta \mathrm{S} 243 \mathrm{~F} / \Delta \mathrm{H} 450 \mathrm{~F}$ & Heterozigose composta & 44 \\
\hline$\Delta 1449$ delC & $\Delta \mathrm{H} 450 \mathrm{~F}$ & Homozigose & 44 \\
\hline$\Delta 1784 \mathrm{C}>\mathrm{T} / \Delta 1449 \mathrm{delC}$ & $\Delta \mathrm{S} 562 \mathrm{~L} / \Delta \mathrm{H} 450 \mathrm{~F}$ & Heterozigose composta & 44 \\
\hline$\Delta 1473 C>T$ & $\Delta \mathrm{R} 492 \mathrm{X}$ & Homozigose & 46 \\
\hline$\Delta$ 1439ins $T$ & $\Delta \mathrm{Y} 447 \mathrm{~F}$ & Homozigose & 45 \\
\hline$\Delta 236 \mathrm{G}>\mathrm{A}$ & $\Delta \mathrm{G} 37 \mathrm{~S}$ & Homozigose & 35 \\
\hline$\Delta 647$ insA $/ \Delta 915$ delC & L174F/S263F & Heterozigose composta & 44 \\
\hline$\Delta$ del $5^{\prime}$ & & Homozigose & 46 \\
\hline$\Delta 1669+1 \mathrm{G} \Delta \quad \mathrm{A}$ & Splicing anormal & Homozigose & 45 \\
\hline$\Delta 18-1 \mathrm{G} \Delta \mathrm{A}$ & Splicing anormal & Homozigose & 36 \\
\hline$\Delta 1627 \mathrm{delG} / \Delta 1570-1 \mathrm{G} \Delta \quad \mathrm{A}$ & V543F/Splicing anormal & Heterozigose composta & 38 \\
\hline
\end{tabular}


Tabela 2. Mutações no receptor do mineralocorticóide descritas em pacientes com PHA1.

\begin{tabular}{|c|c|c|c|c|}
\hline Mutação & Éxon & Herança & Tipo & Referências \\
\hline$\Delta \mathrm{G} 1226$ & 2 & Esporádica & frameshift & 27 \\
\hline$\Delta \mathrm{T} 1597$ & 2 & $\mathrm{AD}$ & frameshift & 27 \\
\hline S163X & 2 & Esporádica & nonsense & 49 \\
\hline R537X & 2 & $A D$ & nonsense & 27 \\
\hline 537del 8bp & 2 & AD & frameshift & 1 \\
\hline 1354Ins T & 2 & $A D$ & frameshift & 1 \\
\hline C436X & 2 & $A D$ & nonsense & 50 \\
\hline Del parcial éxon 2 & 2 & Esporádica & deleção & 53 \\
\hline 1715InsA & 2 & Esporádica & frameshift & 52 \\
\hline R590X & 3 & $A D$ & nonsense & 52 \\
\hline G633R & 3 & $A D$ & missense & 1 \\
\hline C645X & 4 & Esporádica & nonsense & 1 \\
\hline Q776R & 5 & $A D$ & missense & 1 \\
\hline $2581 \mathrm{G}>A$ & 5 & $A D$ & Alteração de splicing & 52 \\
\hline $2587+3$ delA & 5 & $A D$ & Alteração de splicing & 27 \\
\hline S818L & 6 & Esporádica & missense & 52 \\
\hline $2681 \operatorname{lns} A$ & 6 & $A D$ & frameshift & 52 \\
\hline L924P & 8 & $A D$ & missense & 47 \\
\hline 2871Ins C & 9 & Esporádica & frameshift & 48 \\
\hline R947X & 9 & $A D$ & nonsense & 51 \\
\hline Q967X & 9 & $A D$ & nonsense & 52 \\
\hline L979P & 9 & $A D$ & missense & 1 \\
\hline
\end{tabular}

AD: autossômica dominante.

ENaC não-dependente do MR. O mecanismo exato dessa estimulação, entretanto, não foi elucidado (54). Outra hipótese seria que o transporte de sódio através do $\mathrm{ENaC}$ seja acoplado ao transporte de potássio pelo canal secretor de potássio (ROMK). Como o ROMK é expresso somente após o nascimento, isso aumentaria a eficiência do sistema renina-angiotensina-aldosterona no transporte eletrolítico. Possivelmente, esse possa ser um mecanismo fisiológico do aumento da capacidade de transporte de sódio e potássio mediado pelo MR após o período perinatal $(2,55)$.

\section{Receptor do mineralocorticóide}

$\mathrm{O}$ MR pertence à superfamília dos receptores nucleares, da qual fazem parte os outros receptores de hormônios esteróides (glicocorticóides, progesterona, estrogênio e androgênios), o receptor dos hormônios tireoidianos, o receptor do ácido retinóico, o receptor da vitamina $\mathrm{D}$ e os chamados receptores nucleares órfãos, cujos ligantes ainda não foram identificados $(56,57)$. O MR atua como fator de transcrição dependente da ligação ao hormônio (aldosterona), exercendo seus efeitos através da indução ou repressão de genes-alvo específicos (58).

O gene do $M R$ está localizado no cromossomo
4 q31.1 e possui aproximadamente 450 quilobases (kb), sendo composto por dez éxons (figura 2). Os éxons $1 \Delta$ e $1 \Delta$ são compostos somente pela seqüência 5' não-traduzida, onde estão localizadas duas regiões promotoras distintas. A porção amino-terminal do receptor é codificada pelo éxon 2 , o qual contém 2 pares de bases da região 5' não transcrita e 1757 pares de bases de seqüência codificadora. Dois éxons pequenos, 3 e 4, codificam o domínio de ligação ao DNA (DBD) composto por dois zinc fingers. Essas estruturas participam da homodimerização, da translocação nuclear e da transativação. $\mathrm{O}$ domínio de ligação ao hormônio (LBD), responsável pela ligação do hormônio específico ao seu receptor, é codificado pelos éxons 5 a 9 (figura 2) $(59,60)$.

\section{Mutações no gene do MR}

Até o momento, 22 mutações inativadoras no gene do MR foram descritas em pacientes com PHAl, tanto em casos esporádicos como familiares (tabela 2). Essas mutações no gene do MR levam à codificação de receptores com ação diminuída ou proteínas anômalas (1,27,47-53). Todas as mutações descritas no gene do MR em pacientes com PHAl foram encontradas em heterozigose, indicando que a haploinsuficiência do 


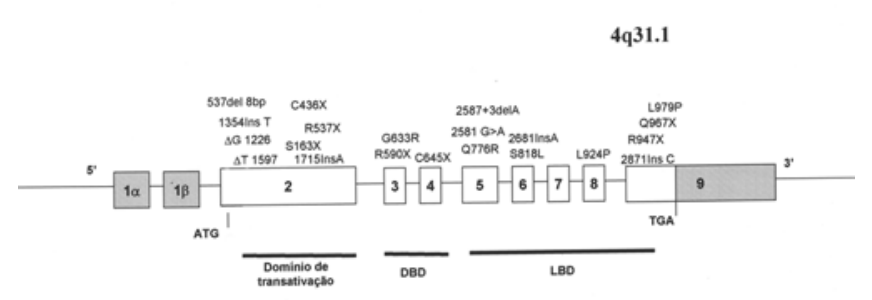

Figura 2. Representação esquemática do gene do receptor do mineralocorticóide, as mutações inativadoras descritas neste gene até o momento e a representação dos domínios funcionais do receptor. O éxon 2 codifica o domínio de transativação, os éxons 3 e 4 codificam o domínio de ligação ao DNA (DBD) e os éxons 5 a 9 codificam o domínio de ligação ao hormônio (LBD).

MR é suficiente para desenvolver as alterações clínicas. Em alguns estudos, foi sugerido que o receptor mutante exerça um efeito dominante negativo sobre o receptor nativo, seja por formar heterodímeros inativos ou por se ligar e inativar fatores de transcrição necessários à atividade do $\mathrm{MR}(2,14)$. Até o momento, entretanto, o estudo funcional de apenas 1 mutação demonstrou efeito dominante negativo do receptor mutante sobre o MR nativo (1).

Arai e cols. (61) realizaram a análise funcional dos polimorfismos 215C>G, I180V e A241V no gene do $M R$ encontrados em um paciente com PHAl em associação a um polimorfismo no íntron 4 do gene codificador da sub-unidade $\Delta$ do ENaC. Em estudo populacional prévio, os polimorfismos $215 \mathrm{C}>\mathrm{G}, \mathrm{I1} 80 \mathrm{~V}$ e A24lV no gene do $M R$ foram encontrados em uma freqüência alélica de 39\%, 48\% e 22\%, respectivamente (62). O estudo funcional demonstrou que, apesar da menor atividade transcricional verificada in vitro, polimorfismos no gene do $M R$, isoladamente, não seriam responsáveis por diminuição da função do receptor. Entretanto, a combinação alélica desses polimorfismos no gene do $M R$ com o polimorfismo no gene da subunidade $\Delta$ do ENaC poderia ocasionar alterações significativas na sensibilidade renal à aldosterona, explicando o fenótipo de PHAl encontrado nesse paciente (61).

Adicionalmente às mutações inativadoras, uma mutação ativadora no éxon 6 do gene do $M R$ (S810L) foi descrita em indivíduos com hipertensão arterial de início em idade precoce e com exacerbação durante a gravidez (63). Essa mutação resulta em ativação constitutiva do MR e altera a especificidade do receptor. A progesterona e outros esteróides sem o grupo 21-hidroxila, normalmente antagonistas do $\mathrm{MR}$, atuam como agonistas potentes do receptor, explicando, dessa forma, a exacerbação da HAS durante a gestação.

\section{Família brasileira com PHA1}

Tivemos a oportunidade de estudar uma família brasileira com a forma renal do $\mathrm{PHAl}$. O caso-índice, um recémnascido do sexo masculino, branco e filho de pais nãoconsangüíneos, apresentou letargia, sucção débil, vômitos e desidratação a partir da $2^{\text {a }}$ semana de vida. Tais sintomas regrediam parcialmente com a administração de soluções de re-hidratação oral. Durante um episódio de desidratação, foi verificada a presença de hiponatremia (126 mEq/L) e hipercalemia $(6,3 \mathrm{mEq} / \mathrm{L})$. A genitália externa era masculina, com testículos tópicos e não havia hipospádia. As concentrações de $17 \mathrm{OH}$-progesterona, ACTH e cortisol estavam normais, excluindo diagnóstico de insuficiência adrenal. As concentrações plasmáticas de aldosterona estavam muito elevadas $(296 \mathrm{ng} / \mathrm{dL}$, valores normais em lactente 6 a $90 \mathrm{ng} / \mathrm{dL})$, bem como da PRA $(7,3 \mathrm{ng} / \mathrm{mL} / \mathrm{h}$, valores normais em dieta normossódica $0,3$ a $1,6 \mathrm{ng} / \mathrm{ml} / \mathrm{h})$, confirmando o diagnóstico de pseudo-hipoaldosteronismo tipo 1. Havia aumento do sódio urinário $(244 \mathrm{mmol} / \mathrm{L}$; valores normais até 40 $\mathrm{nmol} / \mathrm{L})$, porém a concentração de sódio no suor estava normal, excluindo a forma sistêmica do PHAl. O paciente apresentou normalização eletrolítica e ganho pôndero-estatural adequado com a administração de 2 gramas de $\mathrm{NaCl}$ por dia, e a concentração plasmática da aldosterona normalizou-se (66 ng/dL). Aos 10 meses de vida, a suplementação de $\mathrm{NaCl}$ foi suspensa, havendo um aumento nas concentrações plasmáticas de aldosterona e PRA (121,8 ng/dL e 14,8 ng/mL/h, respectivamente), porém a pressão arterial, o crescimento pôndero-estatural e as concentrações plasmáticas de sódio e potássio permaneceram normais. Em relação à história familiar, há relatos de que a mãe da criança apresentou episódios de vômitos e letargia no primeiro ano de vida, que regrediam com a administração de $\mathrm{NaCl}$.

No estudo do gene do $M R$ nesse paciente, encontramos uma substituição de uma base citosina por uma base timina na posição c.3055 (éxon 9), região de codificação do domínio de ligação ao hormônio do receptor (figura 3A). Essa substituição leva à troca de um aminoácido arginina por um códon de parada prematura no códon 947 (R947X), com perda dos últimos 37 aminoácidos do MR. Essa mutação foi encontrada também na mãe do casoíndice, em sua avó materna, em dois tios maternos e em 2 primos maternos, mostrando padrão de herança autossômico dominante (figura 3B). Esta mesma mutação R947X foi descrita previamente em indivíduos turcos com a forma renal do PHAl (51) e, mais recentemente, em uma segunda família turca (62). Investigamos a recorrência da mutação R947X 


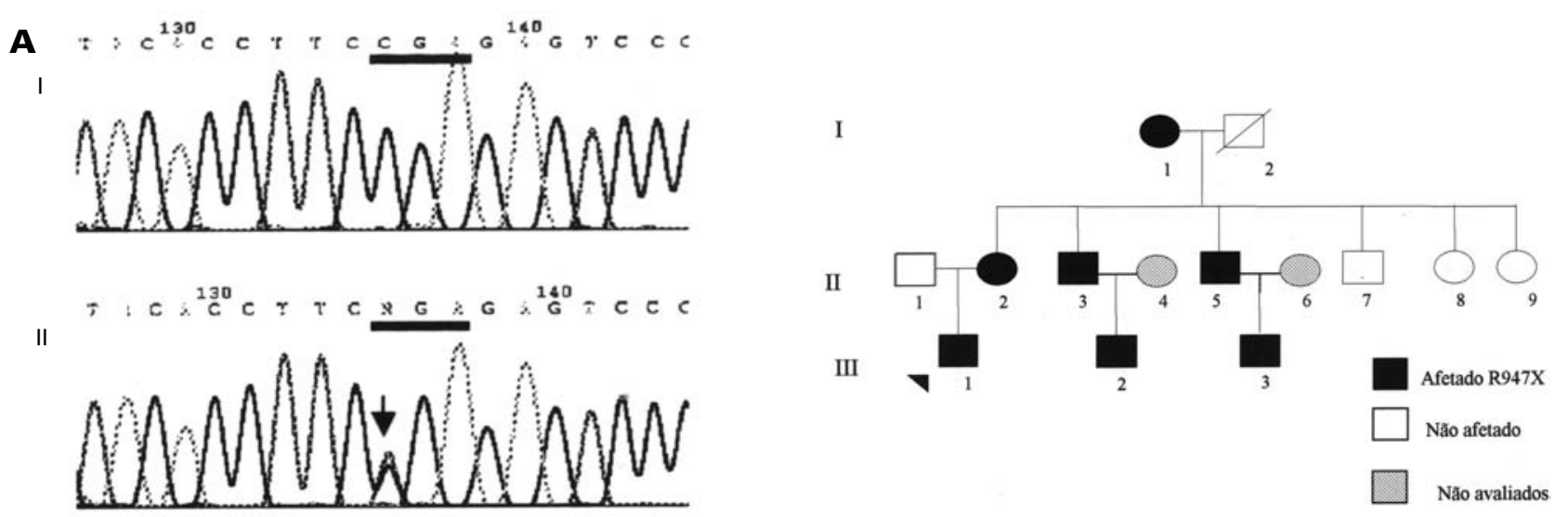

Figura 3. A. I: Cromatograma representativo do éxon 9 do gene $M R$ em sua seqüência de referência (CGA) da região do códon 947. II: Cromatograma mostrando a mutação c3055C > T (R947X) encontrada na família brasileira com a forma renal do PHA1. B. Heredograma representativo da família brasileira com indivíduos afetados por PHA-1. O caso-índice (III1), sua mãe (II2), dois tios maternos (II3 e II5), dois primos (III2 e III3) e a avó materna (I1) apresentam a mutação R947X.

nestas 3 famílias e encontramos haplótipos diferentes segregando com a mutação em cada família, descartando a origem comum da mutação R947X. Demonstramos com esse resultado o primeiro hot spot mutacional no gene do $M R$ (64).

$\mathrm{Na}$ família brasileira, verificamos uma grande variação fenotípica nos indivíduos carreadores de mutações no gene do $M R$, tanto na apresentação clínica como nas concentrações plasmáticas de aldosterona. Vários indivíduos afetados são fenotipicamente normais. Essa variação fenotípica já havia sido descrita em outras famílias com a forma renal do PHAl $(1,49,51,52)$, porém não existem explicações satisfatórias para esse fenômeno. É possível que a co-existência de polimorfismos no gene do $M R$ e nos genes codificadores das sub-unidades do $\mathrm{ENaC}$ seriam responsáveis por essa variação fenotípica, em acordo com resultados prévios publicados por Arai e cols. (61). Entretanto, na família brasileira os indivíduos carreadores da mutação R947X apresentam os mesmos polimorfismos no gene do $M R$ (64), sendo, portanto, improvável a participação de polimorfismos na região codificadora do gene do $M R$ na variação fenotípica encontrada. A presença de mutações ou polimorfismos em genes codificadores de outras proteínas que participam do transporte de sódio em tecidos epiteliais, como Nedd4-2, GILZ, CHIFe KiRas-A, poderia ser responsável por essa variação fenotípica.

\section{CONCLUSŌES E PERSPECTIVAS FUTURAS}

O PHAl compreende duas entidades clínica e geneticamente distintas. Alterações nos genes codificadores das sub-unidades do $\mathrm{ENaC}$ levam à forma sistêmica do PHAl com padrão de herança autossômico recessivo. A forma restrita aos rins ocorre por mutações inativadoras do gene do $M R$. Novos estudos são necessários para o entendimento da história natural da doença visando uma intervenção terapêutica mais precoce, evitando dessa forma episódios graves de desidratação no período neonatal. Análises da correlação genótipo-fenótipo são necessárias para identificação de indivíduos susceptíveis a formas mais graves de apresentação fenotípica do PHAl.

A investigação genética dos indivíduos afetados pelo PHAl pode ser útil para a identificação de outros genes envolvidos nessa doença em famílias sem mutações no gene do $M R$ ou nos genes codificadores do $\mathrm{ENaC}$. Com esses estudos, poderemos não somente entender melhor a patogênese da doença, como também compreender os mecanismos envolvidos na regulação do transporte transepitelial de sódio e na regulação da pressão arterial. É possível que estes conhecimentos possam ser úteis no desenvolvimento de novas drogas para o tratamento da hipertensão arterial sistêmica e da insuficiência cardíaca.

\section{REFERÊNCIAS}

1. Sartorato $P$, Lapeyraque $A L$, Armanini D, Kuhnle U, Khaldi $Y$, Salomon R, et al. Different inactivating mutations of the mineralocorticoid receptor in fourteen families affected by type I pseudohypoaldosteronism. J Clin Endocrinol Metab 2003;88(6):2508-17.

2. Geller DS. Mineralocorticoid resistance. Clin Endocrinol (Oxf) 2005;62(5):513-20.

3. Booth RE, Johnson JP, Stockand JD. Aldosterone. Adv Physiol Educ 2002;26(1-4):8-20.

4. Joels M. Corticosteroid actions in the hippocampus. J Neuroendocrinol 2001;13(8):657-69.

5. Zennaro MC, Le Menuet D, Viengchareun S, Walker F, Ricquier D, Lombes M. Hibernoma development in transgenic mice identifies brown adipose tissue as a novel target of 
aldosterone action. J Clin Invest 1998;101(6):1254-60.

6. Penfornis $P$, Viengchareun $S$, Le Menuet $D$, Cluzeaud $F$, Zennaro $M C$, Lombes $M$. The mineralocorticoid receptor mediates aldosterone-induced differentiation of T37i cells into brown adipocytes. Am J Physiol Endocrinol Metab 2000;279(2):E386-94.

7. Viengchareun S, Penfornis P, Zennaro MC, Lombes M. Mineralocorticoid and glucocorticoid receptors inhibit UCP expression and function in brown adipocytes. Am J Physiol Endocrinol Metab 2001;280(4):E640-9.

8. Funder J. Mineralocorticoids and cardiac fibrosis: the decade in review. Clin Exp Pharmacol Physiol 2001:28(12):1002-6.

9. Taddei S, Virdis A, Mattei P, Salvetti A. Vasodilation to acetylcholine in primary and secondary forms of human hypertension. Hypertension 1993;21(6 Pt 2):929-33.

10. Brilla CG, Weber KT. Mineralocorticoid excess, dietary sodium, and myocardial fibrosis. J Lab Clin Med 1992;120(6):893-901.

11. Connell JM, Davies E. The new biology of aldosterone. J Endocrinol 2005;186(1):1-20.

12. Pitt B, Zannad F, Remme WJ, Cody R, Castaigne A, Perez A, et al. The effect of spironolactone on morbidity and mortality in patients with severe heart failure. Randomized Aldactone Evaluation Study Investigators. N Engl J Med 1999;341(10):709-17.

13. Pitt B, Stier CT Jr, Rajagopalan S. Mineralocorticoid receptor blockade: new insights into the mechanism of action in patients with cardiovascular disease. J Renin Angiotensin Aldosterone Syst 2003;4(3):164-8.

14. Zennaro MC, Lombes M. Mineralocorticoid resistance. Trends Endocrinol Metab 2004;15(6):264-70.

15. Pearce D, Bhargava A, Cole TJ. Aldosterone: its receptor, target genes, and actions. Vitam Horm 2003;66:29-76.

16. Farman N, Rafestin-Oblin ME. Multiple aspects of mineralocorticoid selectivity. Am J Physiol Renal Physiol 2001;280(2):F181-92.

17. Verrey F, Pearce D, Pfeiffer R, Spindler B, Mastroberardino L, Summa V, et al. Pleiotropic action of aldosterone in epithelia mediated by transcription and post-transcription mechanisms. Kidney Int 2000;57(4):1277-82.

18. Spindler B, Mastroberardino L, Custer M, Verrey F. Characterization of early aldosterone-induced RNAs identified in A6 kidney epithelia. Pflugers Arch 1997:434(3):323-31.

19. Naray-Fejes-Toth A, Canessa C, Cleaveland ES, Aldrich G, Fejes-Toth G. Sgk is an aldosterone-induced kinase in the renal collecting duct. Effects on epithelial $\mathrm{Na}+$ channels. $\mathbf{J}$ Biol Chem 1999;274(24):16973-8.

20. Bhargava A, Fullerton MJ, Myles K, Purdy TM, Funder JW, Pearce D, et al. The serum- and glucocorticoid-induced kinase is a physiological mediator of aldosterone action. Endocrinology 2001:142(4):1587-94

21. Robert-Nicoud M, Flahaut M, Elalouf JM, Nicod M, Salinas M, Bens $\mathrm{M}$, et al. Transcriptome of a mouse kidney cortical collecting duct cell line: effects of aldosterone and vasopressin. Proc Natl Acad Sci USA 2001;98(5):2712-6.

22. Boulkroun S, Fay M, Zennaro MC, Escoubet B, Jaisser F, BlotChabaud $\mathrm{M}$, et al. Characterization of rat NDRG2 (N-Myc downstream regulated gene 2 ), a novel early mineralocorticoid-specific induced gene. J Biol Chem 2002;277(35):31506-15.

23. Le Menuet D, Viengchareun S, Muffat-Joly M, Zennaro MC, Lombes M. Expression and function of the human mineralocorticoid receptor: lessons from transgenic mouse models. Mol Cell Endocrinol 2004;217(1-2):127-36.

24. Gormley K, Dong Y, Sagnella GA. Regulation of the epithelial sodium channel by accessory proteins. Biochem 2003;371(Pt 1):1-14.

25. Funder J. The nongenomic actions of aldosterone. Endocr Rev 2005;26(3):313-21.

26. Cheek DB, Perry JW. A salt wasting syndrome in infancy. Arch Dis Child 1958;33(169):252-6.

27. Geller DS, Rodriguez-Soriano J, Vallo Boado A, Schifter S, Bayer M, Chang SS, et al. Mutations in the mineralocorticoid receptor gene cause autosomal dominant pseudohypoaldos- teronism type I. Nat Genet 1998;19(3):279-81

28. Kuhnle $U$, Nielsen MD, Tietze $\mathrm{HU}$, Schroeter $\mathrm{CH}$ Schlamp $\mathrm{D}$, Bosson D, et al. Pseudohypoaldosteronism in eight families: different forms of inheritance are evidence for various genetic defects. J Clin Endocrinol Metab 1990;70(3):638-41.

29. Armanini D, Wehling M, Da Dalt L, Zennaro M, Scali U, Keller $U$, et al. Pseudohypoaldosteronism and mineralocorticoid receptor abnormalities. J Steroid Biochem Mol Biol 1991:40(1-3):363-5.

30. Hanukoglu A. Type I pseudohypoaldosteronism includes two clinically and genetically distinct entities with either renal or multiple target organ defects. J Clin Endocrinol Metab 1991;73(5):936-44.

31. Hanukoglu A, Bistritzer T, Rakover Y, Mandelberg A. Pseudohypoaldosteronism with increased sweat and saliva electrolyte values and frequent lower respiratory tract infections mimicking cystic fibrosis. J Pediatr 1994;125(5 Pt 1):752-5.

32. Oberfield SE, Levine LS, Carey RM, Bejar R, New MI. Pseudohypoaldosteronism: multiple target organ unresponsiveness to mineralocorticoid hormones. J Clin Endocrinol Metab 1979;48(2):228-34.

33. Savage MO, Jefferson IG, Dillon MJ, Milla PJ, Honour JW, Grant DB. Pseudohypoaldosteronism: severe salt wasting in infancy caused by generalized mineralocorticoid unresponsiveness. J Pediatr 1982;101(2):239-42.

34. Bosson D, Kuhnle U, Mees N, Ramet J, Vamos E, Vertongen $\mathrm{F}$, et al. Generalized unresponsiveness to mineralocorticoid hormones: familial recessive pseudohypoaldosteronism due to aldosterone-receptor deficiency. Acta Endocrinol Suppl (Copenh) 1986;279:376-80.

35. Chang SS, Grunder S, Hanukoglu A, Rosler A, Mathew PM, Hanukoglu I, et al. Mutations in subunits of the epithelial sodium channel cause salt wasting with hyperkalaemic acidosis, pseudohypoaldosteronism type 1. Nature Genet 1996; $12: 248-53$.

36. Strautnieks SS, Thompson RJ, Gardiner RM, Chung E. A novel splice-site mutation in the gamma subunit of the epithelial sodium channel gene in three pseudohypoaldosteronism type 1 families. Nature Genet 1996;13:248-50.

37. Arai K, Zachman K, Shibasaki T, Chrousos GP. Polymorphisms of amiloride-sensitive sodium channel subunits in five sporadic cases of pseudohypoaldosteronism: do they have pathologic potential? J Clin Endocrinol Metab 1999;84:2434-7.

38. Adachi M, Tachibana K, Asakura Y, Abe S, Nakae J, Tajima T, et al. Compound heterozygous mutations in the gamma subunit gene of ENaC (1627delG and 1570-1G $\rightarrow$ A) in one sporadic Japanese patient with a systemic form of pseudohypoaldosteronism type 1. J Clin Endocrinol Metab 2001;86(1):9-12.

39. Kellenberger S, Schild L. Epithelial sodium channel/degenerin family of ion channels: a variety of functions for a shared structure. Physiol Rev 2002;82(3):735-67.

40. Rossier BC, Canessa CM, Schild L, Horisberger JD. Epithelial sodium channels. Curr Opin Nephrol Hypertens 1994;3(5):487-96.

41. Horisberger JD, Canessa CM, Rossier BC. The epithelial sodium channel recent developments. Cell Physiol Biochem 1993:32:283-94.

42. Canessa CM, Schild L, Buell G, Thorens B, Gautschi I, Horisberger JD, et al. Amiloride-sensitive epithelial $\mathrm{Na}+$ channel is made of three homologous subunits. Nature 1994;367(6462):463-7.

43. Kerem E, Bistritzer T, Hanukoglu A, Hofmann T, Zhou Z, Bennett $W$, et al. Pulmonary epithelial sodium-channel dysfunction and excess airway liquid in pseudohypoaldosteronism. N Engl J Med 1999;341(3):156-62.

44. Schaedel C, Marthinsen L, Kristoffersson AC, Kornfalt R, Nilsson $\mathrm{KO}$, Orlenius $\mathrm{B}$, et al. Lung symptoms in pseudohypoaldosteronism type 1 are associated with deficiency of the alpha-subunit of the epithelial sodium channel. J Pediatr 1999;135(6):739-45.

45. Saxena A, Hanukoglu I, Saxena D, Thompson RJ, Gardiner RM, Hanukoglu A. Novel mutations responsible for autosomal recessive multisystem pseudohypoaldosteronism and sequence variants in epithelial sodium channel alpha-, beta-, and gamma-subunit genes. J Clin Endocrinol Metab 
2002;87(7):3344-50.

46. Bonny O, Knoers N, Monnens L, Rossier BC. A novel mutation of the epithelial $\mathrm{Na}+$ channel causes type 1 pseudohypoaldosteronism. Pediatr Nephrol 2002;17(10):804-8.

47. Tajima $T$, Kitagawa $H$, Yokoya $S$, Tachibana K, Adachi M Nakae J, et al. A novel missense mutation of mineralocorticoid receptor gene in one Japanese family with a renal form of pseudohypoaldosteronism type 1. J Clin Endocr Metab 2000:85:4690-4.

48. Viemann M, Peter M, Lopez-Siguero JP, Simic-Schleicher G, Sippell WG. Evidence for genetic heterogeneity of pseudohypoaldosteronism type 1: identification of a novel mutation in the human mineralocorticoid receptor in one sporadic case and no mutations in two autosomal dominant kindreds. $J$ Clin Endocr Metab 2001;86:2056-9.

49. Riepe FG, Krone N, Morlot M, Ludwig M, Sippell WG, Partsch CJ. Identification of a novel mutation in the human mineralocorticoid receptor gene in a German family with autosomaldominant pseudohypoaldosteronism type 1: further evidence for marked interindividual clinical heterogeneity. J Clin Endocrinol Metab 2003;88(4):1683-6.

50. Nystrom AM, Bondeson ML, Skanke N, Martensson J, Stromberg B, Gustafsson J, et al. A novel nonsense mutation of the mineralocorticoid receptor gene in a Swedish family with pseudohypoaldosteronism type । (PHA1). J Clin Endocrinol Metab 2004;89(1):227-31.

51. Riepe FG, Krone N, Morlot M, Peter M, Sippell WG, Partsch CJ. Autosomal-dominant pseudohypoaldosteronism type 1 in a Turkish family is associated with a novel nonsense mutation in the human mineralocorticoid receptor gene. J Clin Endocrinol Metab 2004;89(5):2150-2.

52. Geller DS, Zhang J, Zennaro MC, Vallo-Boado A, RodriguezSoriano J, Furu L, et al. Autosomal dominant pseudohypoaldosteronism type 1: mechanisms, evidence for neonatal lethality, and phenotypic expression in adults. J Am Soc Nephrol 2006;17(5):1429-36.

53. Sartorato $\mathrm{P}$, Cluzeaud F, Fagart J, Viengchareun S, Lombes $M$, Zennaro MC. New naturally occurring missense mutations of the human mineralocorticoid receptor disclose important residues involved in dynamic interactions with deoxyribonucleic acid, intracellular trafficking, and ligand binding. Mol Endocrinol 2004;18(9):2151-65.

54. Schulz-Baldes A, Berger S, Grahammer F, Warth R, Goldschmidt I, Peters J, et al. Induction of the epithelial $\mathrm{Na}+$ channel via glucocorticoids in mineralocorticoid receptor knockout mice. Pflugers Arch 2001;443(2):297-305.

55. Benchimol C, Zavilowitz B, Satlin LM. Developmental expression of ROMK mRNA in rabbit cortical collecting duct. Pediatr Res 2000;47(1):46-52.

56. Evans WH, Bergeron JJ. Nuclear receptors: a re-evaluation. Trends Biochem Sci 1988;13(1):7-8.
57. Danielian PS, White R, Lees JA, Parker MG. Identification of a conserved region required for hormone dependent transcriptional activation by steroid hormone receptors. EMBO J 1992; 11(3):1025-33.

58. Mangelsdorf DJ, Thummel C, Beato M, Herrlich P, Schutz G, Umesono $\mathrm{K}$, et al. The nuclear receptor superfamily: the second decade. Cell 1995;83(6):835-9.

59. Zennaro MC, Keightley MC, Kotelevtsev Y, Conway GS, Soubrier F, Fuller PJ. Human mineralocorticoid receptor genomic structure and identification of expressed isoforms. J Biol Chem 1995;270(36):21016-20.

60. Pascual-Le Tallec L, Lombes M. The mineralocorticoid receptor: a journey exploring its diversity and specificity of action. Mol Endocrinol 2005; 19(9):2211-21.

61. Arai K, Nakagomi Y, Iketani M, Shimura Y, Amemiya S, Ohyama K, et al. Functional polymorphisms in the mineralocorticoid receptor and amirolide-sensitive sodium channel genes in a patient with sporadic pseudohypoaldosteronism. Hum Genet 2003;112(1):91-7.

62. Arai K, Tsigos C, Suzuki Y, Irony I, Karl M, Listwak S, et al. Physiological and molecular aspects of mineralocorticoid receptor action in pseudohypoaldosteronism: a responsiveness test and therapy. J Clin Endocrinol Metab 1994;79(4):1019-23.

63. Geller DS, Farhi A, Pinkerton N, Fradley M, Moritz M, Spitzer $A$, et al. Activating mineralocorticoid receptor mutation in hypertension exacerbated by pregnancy. Science 2000;289(5476):119-23.

64. Fernandes-Rosa FL, de Castro M, Latronico AC, Sippell W, Riepe FG, Antonini SR. Recurrence of the R947X mutation in unrelated families with autosomal dominant pseudohypoaldosteronism type 1: evidence for a mutational hot spot in the mineralocorticoid receptor gene. J Clin Endocrinol Metab 2006;91(9):3671-5.

\section{Endereço para correspondência:}

Sonir R.R. Antonini

Departamento de Puericultura e Pediatria

Hospital das Clínicas

Faculdade de Medicina de Ribeirão Preto - USP

Av. Bandeirantes 3900

14049-900 Ribeirão Preto, SP

E-mail: antonini@fmrp.usp.br 